\title{
Hispanic population: forgotten hereditary breast and ovarian cancer high risk group?
}

\begin{abstract}
Pathogenic variants in the BRCA1 and $B R C A 2$ genes have been recognized as major contributors to breast and ovarian cancer risk since the mid-1990s. While the prevalence of $B R C A 1$ and BRCA2 mutations in the general population is estimated at 1:400, the prevalence in the Hispanic population has not been established. However, the significantly earlier age of breast cancer onset and the higher prevalence of triple-negative breast tumors compared to non-Hispanic White women are consistent with a high prevalence of BRCA1/2 mutations in the Hispanic population. Recent studies have shown that a handful of highly recurrent $B R C A 1 / 2$ mutations are responsible for most of the hereditary risk of breast and ovarian cancer in Hispanic women. Two mutations in particular, BRCA1 185delAG and BRCA1 exon9-12 del, are the most prevalent and can be traced back to Spanish and Amerindian founder populations respectively.
\end{abstract}

Keywords: breast, ovarian, cancer, brcal, brca2, palb2, stk11, cdh1, tp53, pten, Hispanic
Volume 2 Issue 3 - 2015

Adrian Vilalta

Correspondence: Adrian Vilalta, Email Adrian.Vilalta@gmail.com

Received: May 21, 2015 | Published: July 17, 2015

\section{Introduction}

\section{Breast and ovarian cancer in hispanic population}

An estimated 232,670 women will be diagnosed with breast cancer and 40,000 will die from the disease in the United States in 2014. ${ }^{1}$ Breast cancer in the US is the most common cancer in women, regardless of race or ethnicity and the second leading cause of death from cancer among White, Black, Asian/Pacific Islander and American Indian/Alaska Native women. ${ }^{2}$ Moreover, breast cancer is the most common cause of death from cancer and one of the biggest threats to Hispanic women's health. According to 2012 statistics from the American Cancer Society, 17,100 new cases of breast cancer were diagnosed in Hispanic women in the US; this represents $29 \%$ of all the cancer diagnoses in Hispanic women for the year. At the same time it is estimated that 2,400 Hispanic women died of the disease the same year. ${ }^{3,4}$ This makes breast cancer the deadliest cancer for Hispanic women in the US. During the same year, approximately 2,000 new cases of ovarian cancer were reported in women of Hispanic background; this represents $3 \%$ of all new cancer cases in this group. Ovarian cancer resulted in about 1,000 deaths of Hispanic women during 2012 or $6 \%$ of the total number of cancer-related deaths for the year. ${ }^{4}$

\section{Hispanic population is diverse}

The Hispanic population is the largest and fastest growing minority group in the US. According to the US Census Bureau population estimates of July 1, 2013, Hispanics represented approximately 17\% of the US population or about 54 million individuals. ${ }^{5}$ The Hispanic population is projected to reach 128.8 million by 2060 , constituting approximately $31 \%$ of the US population. ${ }^{6}$ The Hispanic population in the US is diverse in origin. According to 2013 figures from the Pew Research Center, most of the Hispanic population in the US traces their origin to Mexico (64.6\%). Other regions of origin include Puerto Rico (9.5\%), Central America (8.3\%), South America (5.2\%), Cuba (3.6\%), Dominican Republic (2.9\%) and Spain (1.4\%). ${ }^{7,8}$ The cancer burden among Hispanics living in the US is similar to that observed in their countries of origin. ${ }^{4}$ For example, the incidence of breast cancer in Mexico in 2009 was 15 per 100,000 women with the highest incidence of the disease in the northern and central states (Coahuila, 18 per 100,000; Federal District, 17 per 100,000 and Nuevo León 14 per 100,000). ${ }^{9}$

\section{Improving clinical outcomes in Hispanic women}

The incidence of breast cancer in Hispanic women is $26 \%$ lower than non-Hispanic White women. This is most likely due to differences in reproductive choices such as age of first pregnancy, number of pregnancies and rate of hormone supplementation use. ${ }^{10}$ However, in Hispanic women breast cancer is often detected when it has reached a more advanced stage compared to non-Hispanic White women (64\% in non-Hispanic Whites detected at local stage versus $56 \%$ in Hispanics). ${ }^{4}$ A contributing factor to this disparity is the fact that Hispanic women are younger on average (under 50years of age) at the time of diagnosis. ${ }^{11}$ This fact highlights the need to increase awareness about the benefits of self-examination and mammograms as well as the need for better access to preventive health care in this population group.

\section{Hereditary breast and ovarian cancer risk}

Cancer can occur as a result of various factors, including inherited and acquired genetic mutations, diet, lifestyle choices and age. ${ }^{10,12}$ It has long been recognized that cancer risk is higher in some families and ethnic groups as compared to the population at large, suggesting a genetic component to the overall breast cancer risk. Studies of high-risk breast and ovarian cancer families led to the discovery of the $B R C A 1$ and $B R C A 2$ genes in the mid 1990s. BRCA1 and BRCA2 are the two genes with the strongest association with increased risk for breast and ovarian cancer accounting for approximately $5-7 \%$ of all breast cancer cases $^{13}$ and $8-13 \%$ of epithelial ovarian cancer cases; ${ }^{14}$ thus mutations in $B R C A 1 / 2$ lead to the so called hereditary breast and ovarian cancer syndrome (HBOC). Furthermore, mutations in BRCA1 and BRCA2 increase the risk of male breast cancer as well. It is estimated that $B R C A 2$ mutations confer a risk of male breast cancer of 6 in 100 while $B R C A 1$ mutations provide a risk of 1 in $100 .{ }^{1} B R C A 1$ and $B R C A 2$ are tumor suppressors with well-defined roles in DNA repair. ${ }^{15-17}$ Defects 
in the DNA repair mechanisms triggers a cascade of DNA sequence alterations that result in an increased risk for cancer. Although $B R C A 1$ and $B R C A 2$ are the most recognized genes with an association with breast cancer, mutations in other genes need to be considered in non$B R C A 1 / 2$ high-risk families. Most notably amongst these are genes previously associated with well-studied genetic disease syndromes, i.e., PTEN (Cowden), TP53 (Li-Fraumeni), CDH1 (hereditary diffuse gastric cancer) and STK11(Peutz-Jehgers). ${ }^{18}$ In addition, a recent (August, 2014), large study of hereditary breast cancer patients established the $P A L B 2$ gene as a key contributor to hereditary breast cancer. ${ }^{19-21}$

\section{$B R C A I / 2$ and ethnicity}

Prevalence of $B R C A 1 / 2$ in the general population in the US has been reported to be approximately 1 in $400 .{ }^{22}$ Large population studies $^{23,24}$ of breast cancer survivors under the age of 65 revealed strong ethnic differences in the prevalence of pathogenic mutations in BRCA1 and BRCA2 gene (Table 1). Clearly, based on the data presented on Table 1, prevalence of BRCA1 mutations in Hispanic women is second only to Ashkenazi women. This is consistent with recent reports about breast cancer in Mexico. According to recent studies, ${ }^{11}$ patients with breast cancer in Mexico are younger at the time of disease diagnosis (under 50years of age) which is on average at least a decade earlier than in Caucasian women. In addition, Hispanic cancer patients have a higher prevalence of so called triple-negative breast cancer compared to non-Hispanic Whites in the US. According to Lara-Medina et al. ${ }^{11}$ the prevalence of triple-negative tumors in Hispanic women is about $23 \%$ compared to a reported prevalence of $10-13 \%$ in Caucasian patients. Triple-negative tumors lack estrogen and progesterone receptors as well as HER2 (ER-, PR-, HER2-). These tumors do not respond to hormonal therapies or to medications that target HER2 and are therefore associated with poor prognoses. Both the earlier ages of onset as well as the increased proportion of triple negative tumors are consistent with a larger proportion of cancer cases attributable to $B R C A 1 / 2$ mutations.

Table I Prevalence of BRCAI and BRCA2 mutations in women with breast cancer by ethnic group within US..$^{23,24}$

\begin{tabular}{lll}
\hline Ethnicity & BRCAI & BRCA2 \\
\hline Ashkenazi Jewish & $8.3-10.2 \%$ & I.I0\% \\
Hispanic & $3.50 \%$ & Data not available \\
Caucasian (non-Ashkenazi Jewish) & $2.2-2.4 \%$ & $2.20 \%$ \\
African-American & $1.3-1.4 \%$ & $2.60 \%$ \\
Asian-American & $0.50 \%$ & Data not available
\end{tabular}

BRCAI/2 highly recurrent pathogenic variants in Hispanics

$B R C A 1 / 2$ pathogenic variants in Hispanics reflect the ethnic admixtures that have taken place over the last 500 years. For example, in the Mexican population, two pathogenic variants in BRCAl canrepresent up to $\sim 40 \%$ of the observed $B R C A 1 / 2$ pathogenic variants (185delAG and ex9-12 del). ${ }^{25,26}$ Haplotype analysis shows that the 185delAG mutation is the same founder mutation seen in several Jewish populations including Ashkenazi and Sephardic. ${ }^{27}$ It is generally believed that this mutation was introduced in the Mexican gene pool through immigration of Spanish Jewish converts to colonial Mexico. On the other hand, the highly prevalent ex9-12del (also known as ex8-11del) mutation is believed to have arisen in the Amerindian population about 74 generations ago or approximately 1,480 years ago. ${ }^{25}$ The unusually high prevalence of this mutation in the population of central Mexico ${ }^{28}$ is certainly consistent with this analysis. Table 2 presents a list of the top six recurrent $B R C A 1$ and $B R C A 2$ pathogenic variants observed in the Hispanic population.

Table 2 Top six recurrent BRCAI/2 pathogenic in hispanics. . $^{25,26,28,30}$

\begin{tabular}{|c|c|c|c|c|}
\hline Gene & $\begin{array}{l}\text { Common } \\
\text { name }\end{array}$ & cHGVS & pHGVS & $\begin{array}{l}\text { Proportion of BRCA I/2 } \\
\text { mutations (\%) }\end{array}$ \\
\hline & I85delAG & NM_007294.3:c.68_69delAG & NP_009225.I:p.E23Vfs & $2.5-28.6 \%$ \\
\hline & ex9-12del & - & - & $6.9-32.5 \%$ \\
\hline \multirow[t]{3}{*}{ BRCAI } & S955X & NM_007294.3: c.2864C>A & NP_009225.I:p.S955* & $2.1-7.1 \%$ \\
\hline & RI443X & NM_007294.3: c.4327C>T & NP_009225.I:p.RI443* & $3.2-8.8 \%$ \\
\hline & 2552delC & NM_007294.3:c.2433delC & NP_009225.I:p.K8I2Rfs & $2.1-7.1 \%$ \\
\hline $\mathrm{BRCA} 2$ & 3492ins T & NM_000059.3: c.3264dupT & NP_000050.2:p.Q1089Sfs & $5.3-5.9 \%$ \\
\hline
\end{tabular}

\section{Conclusion}

Breast cancer among Hispanic women is a major health concern. Based on current population trends in the US, breast cancer in Hispanics is bound to have a stronger impact in overall health care burden in the US. Better access to preventive health care, regular breast self-examination and extensive use of mammography are bound to have a strong positive impact. In addition, genetic testing for hereditary breast cancer risk should be an important component of the health care strategy since it can identify women that would

require more frequent screening and potentially other risk reduction strategies. Genetic testing of high-risk Hispanic patients using a targeted mutation panel should be a cost-effective approach given the high frequency of a few BRCA1 and BRCA2 mutations in this population. Patients for whom testing is most beneficial are those that satisfy the NCCN testing recommendations. ${ }^{29}$

\section{Acknowledgements}

None. 


\section{Conflict of interest}

Author declares that there is no conflict of interest.

\section{References}

1. American Cancer Society. Cancer Facts \& Figures 2014. American Cancer Society. 2014.

2. Centers for Disease Control and Prevention, Breast Cancer Statistics.

3. National Cancer Institute, Useful Information about Breast Cancer for Hispanic Women. National Cancer Institute.

4. American Cancer Society Inc. Cancer Facts \& Figures for Hispanics/ Latinos 2012-2014. American Cancer Society.

5. US Census Bureau. Facts for Features: Hispanic Heritage Month: Sept, 15-Oct, 15, 2014. US Census Bureau; 2014.

6. US Census Bureau. U.S. Census Bureau Projections Show a Slower Growing, Older, More Diverse Nation a Half Century from Now. Newsroom Archive. 2012.

7. Pew Research Center. Population, by Race and Ethnicity: 2000 and 2011.

8. Pew Hispanic Center. Diverse Origins: The Nation's 14 Largest Hispanic-Origin Groups. 2013.

9. Chavarri-Guerra Y, Villarreal-Garza C, Liedke PE, et al. Breast cancer in Mexico: a growing challenge to health and the health system. Lancet Oncol. 2012;13(8):e335-e343.

10. Centers for Disease Control and Prevention (CDC). What are the risks for breast cancer? Centers for Disease Control and Prevention. 2015.

11. Lara-Medina F, Pérez-Sánchez V, Saavedra-Pérez D, et al. Triplenegative breast cancer in Hispanic patients: high prevalence, poor prognosis, and association with menopausal status, body mass index, and parity. Cancer. 2011;117(16):3658-3669.

12. Calle EE, Thun MJ. Obesity and cancer. Oncogene. 2004;23(38):6365-6378.

13. Roy R, Chun J, Powell SN. BRCA1 and BRCA2: different roles in a common pathway of genome protection. Nat Rev Cancer. 2012;12(1):68-78.

14. Liu G, Yang D, Sun Y, et al. Differing clinical impact of BRCA1 and BRCA2 mutations in serous ovarian cancer. Pharmacogenomics. 2012;13:1523-1535.

15. Irminger-Finger I, Siegel BD, Leung WC. The functions of breast cancer susceptibility gene 1 (BRCA1) product and its associated proteins. Biol Chem. 1999;380(2):117-128.

16. O'Donovan PJ, Livingston DM. BRCA1 and BRCA2: breast/ovarian cancer susceptibility gene products and participants in DNA doublestrand break repair. Carcinogenesis. 2010;31(6):961-967.
17. Rosen EM, Fan S, Pestell RG, et al. BRCA1 gene in breast cancer. $J$ Cell Physiol. 2003;196(1):19-41.

18. Smith EC. An overview of hereditary breast and ovarian cancer syndrome. Journal of midwifery \& women's health. 2012;57(6):577-584.

19. Evans MK, Longo DL. PALB2 mutations and breast-cancer risk. N Engl J Med. 2014;371(6):566-568.

20. Antoniou AC, Casadei S, Heikkinen T, et al. Breast-cancer risk in families with mutations in PALB2. The New England Journal of medicine. 2014;371:497-506.

21. Park JY, Zhang F, Andreassen PR. PALB2: The hub of a network of tumor suppressors involved in DNA damage responses. Biochim Biophys Acta. 2014;1846(1):263-275.

22. National Cancer Institute (NCI). Genetics of Breast and Gynecologic Cancers-for health professionals. National Cancer Institute. 2014.

23. Malone KE, Daling JR, Doody DR, et al. Prevalence and predictors of BRCA1 and BRCA2 mutations in a population-based study of breast cancer in white and black American women ages 35 to 64years. Cancer Res. 2006;66(16):8297-8308.

24. John EM, Miron A, Gong G, et al. Prevalence of pathogenic BRCA1 mutation carriers in 5 US racial/ethnic groups. JAMA. 2007;298(24):2869-2876.

25. Weitzel JN, Clague J, Martir-Negron A, et al. Prevalence and type of BRCA mutations in Hispanics undergoing genetic cancer risk assessment in the southwestern United States: a report from the Clinical Cancer Genetics Community Research Network. J Clin Oncol. 2013;31(2):210-216.

26. Weitzel JN, Lagos VI, Herzog JS, et al. Evidence for common ancestral origin of a recurring BRCA1 genomic rearrangement identified in high-risk Hispanic families. Cancer Epidemiol Biomarkers Prev. 2007;16(8):1615-1620.

27. Bar-Sade RB, Kruglikova A, Modan B, et al. The 185delAG BRCA1 mutation originated before the dispersion of Jews in the diaspora and is not limited to Ashkenazim. Hum Mol Genet. 1998;7(5):801-805.

28. Villarreal-Garza C, Alvarez-Gomez RM, Perez-Plasencia C, et al. Significant clinical impact of recurrent BRCA1 and BRCA2 mutations in Mexico. Cancer. 2015;121(3):372-378.

29. NCCN. Genetic/Familial High-Risk Assessment: Breast and Ovarian. 2015

30. Vogel KJ, Atchley DP, Erlichman J, et al. BRCA1 and BRCA2 genetic testing in Hispanic patients: mutation prevalence and evaluation of the BRCAPRO risk assessment model. J Clin Oncol. 2007;25(29):4635-4641 